Годишник Телекомуникации 2019, том 6, с. 161-170

Yearbook Telecommunications 2019, vol. 6, p. 161-170

eISSN 2534-854X

https://telecommunications.nbu.bg/bg/godishnik-telekomunikacii

DOI: https://doi.org/10.33919/YTelecomm.19.6.16

МИЛИМЕТРОВИЯТ ЧЕСТОТЕН ОБХВАТ КАТО ПЕРСПЕКТИВА ЗА 5G МРЕЖИ

\author{
Росен Пасарелски
}

\title{
THE MILLIMETER FREQUENCY RANGE AS A PERSPECTIVE FOR 5G NETWORKS
}

\begin{abstract}
Rosen Pasarelski
Резюме: Масово внедрените към настоящия момент 4G клетъчни мрежи са изправени пред множество предизвикателства. Растящото търсене на мобилни мултимедийни приложения с висока разделителна способност приближава тези мрежи до техните практически граници. 5G мрежите, следващото поколение безжични комуникации са стандартизирани така, че да облекчат тежестта върху настоящата инфраструктура, като предлагат значително по-високи скорости на данни чрез увеличена честотна лента на каналите. Като се има предвид недостигът на достьпни честоти, които традиционно се използват за мобилни комуникации, лентите в милиметровия честотен обхват (mmWave) са доста предизвикателна алтернатива. Тази технологията е крайъгълен камък на предстоящите 5G мрежи, позволявайки по-високи скорости на данни и много по-голяма честотна лента от всякога, но въпреки това, не всяка 5G мрежа задължително ще използва този честотен обхват, поне не през цялото време. Както при всяка нова технология, има неизбежни проблеми, които трябва да се преодолеят. Целта на проучванията и анализите в тази статия е да се систематизират въпроси и решения, свързани с потенциалните проблеми на съвместното използване на спектьра в mmWave честотен обхват, пригодността му за комуникации на дълги разстояния, в затворени помещения, при лоши метеорологични условия, като и биологичните аспекти, като са направени съответни изводи за посрещане на тези предизвикателства.
\end{abstract}

Ключови думи: 5G мрежи, милиметров честотен обхват, проблеми, перспективи

\begin{abstract}
The currently widely used 4G cellular networks face many challenges. The growing demand for high-resolution mobile multimedia applications is bringing these networks to their practical limits. 5G networks, the next generation of wireless communications, are standardized to ease the burden on current infrastructure by offering significantly higher data rates through increased channel bandwidth. Given the lack of accessible frequencies traditionally used for mobile communications, millimeter bandwidths (mmWave) are quite a challenging alternative. This technology is a cornerstone of upcoming $5 \mathrm{G}$ networks, allowing faster data speeds and much higher bandwidth than ever before, but not every $5 \mathrm{G}$ network will necessarily use this frequency band, at least not all the time. As with any new technology, there are unavoidable problems that need to be overcome. The purpose of the research and analysis in this article is to systematize issues and solutions related to the potential problems of spectrum sharing in mmWave frequency range, its suitability for long-distance communications, indoors, in bad weather conditions, as well as biological aspects, and relevant conclusions have been done to meet these challenges.
\end{abstract}

Keywords: $5 \mathrm{G}$ networks, millimeter waves, problems, perspective

\section{1. ВЪВЕДЕНИЕ}

Операторите и доставчиците на мобилни комуникационни услуги са насочили вниманието си към новата $5 \mathrm{G}$ безжична технология, която може да донесе огромен напредък в скоросттите за пренос на данни и надеждността на мобилните устройства. Поважното е, че $5 \mathrm{G}$ може да даде възможност за нова вълна от технологии и приложения, базирани на нова инфраструктура. 5G е много повече от нова технология за достьп. За разлика от предишните мобилни поколения, които бяха дефинирани чрез въздушния 
интерфейс, 5G ще промени фундаментално начините, по който изграждаме, работим и използваме мобилните мрежи от край до край - от основната мрежа (core) до мрежата за радио достъп (RAN), до потребителите (хората) и машините (нещата). Основната новост на 5G ще бъде интегрирането на множество мрежи, обслужващи различни сектори, домейни и приложения, като мултимедия, виртуална реалност (VR)/разширена реалност (AR), комуникации машина - машина (M2M), Интернет на нещата (IoT), автомобилостроенето, т.н. Тези промени ще бъдат революционни, но ще се въвеждат постепенно, за да отговорят на изискванията операторите и да задоволят очакванията за възврьщаемост на инвестициите. Този процес е започнал вече: операторите са възприели визията на 5G, дори и мнозина да нямат подробна пътна карта и осъзнават, че трябва да се подготвят за $5 \mathrm{G}$ сега $[1,10]$.

Милиметровите вълни представляват все по-голям интерес за спьтниковата индустрия и са разпределени за използване от 5G мрежи на Световната конференция по радиосъобщения WRC-2019. Използването на спектьра от mmWave обхват ще бъде съчетано с упльтняване на мрежата и използването на масивни MIMO антени, което ще даде възможност за ултрависоки скорости на достъп. mmWave ще бъдат комбинирани с MEC (Mobile-edge Computing) с цел осигуряване на комуникации с такива скорости и ниска латентност. Новите резолюции, одобрени на WRC-19, посочиха, че за приложенията на IMT с ниска латентност и много висока цифрова скорост ще са необходими по-големи съседни блокове от тези, които са налични в честотни ленти, които преди това са били идентифицирани за използване от администрациите на съобщенията за прилагане на IMT стандарта. Те също така посочиха, че хармонизираните в световен мащаб ленти за IMT са желателни, за да се улесни глобалният роуминг и постигането на икономически ползи.

\section{2. НОВА ЧЕСТОТНА ГРАНИЦА ЗА МОБИЛНИ ШИРОКОЛЕНТОВИ КОМУНИКАЦИИ}

Интернет е най-важният фактор за социалното развитие и икономическия растеж на нашето време. Въпреки това, 5G ще достигне далеч отвъд широколентовия достъп. 5G не е просто ново поколение мобилни технологии, а отправна точка на нова революция в свързаността. Въпреки това, пълният състав на услугите за промяна на живота ще бъде възможен само когато се предостави подходящ спектър.

Милиметровите вълни са радиочестотни вълни в изключително високия честотен обхват от 30 до $300 \mathrm{GHz}$, с дължини на вълните между $10 \mathrm{~mm}$ и $1 \mathrm{~mm}$. В 5G контекст попадат милиметрови вълни между 24 и $71 \mathrm{GHz}$ (двата честотни обхвата $26 \mathrm{GHz}$ и $28 \mathrm{GHz}$ са включени в милиметровия обхват чрез по конвенция). В тези високи диапазони голяма част от спектъра не е разпределена за комуникационни цели, така че те предоставят възможност осигуряване на по-широка честотна лента, респективно за повече канали и постигане на по-високи скорости на данни за един канал.

Очаква се осигуряване на честотни ленти с широчини от порядъка на 100 до 400 $\mathrm{MHz}$ за 5G операторите, в сравнение с 10 до $20 \mathrm{MHz}$ за UHF канали (Bertenyi, 2017). По този начин ще могат едновременно да се обслужват повече потребители. Също така ще се подпомогнат и бизнес моделите, които очакват много по-плътна популация от потребители, вероятно с изискания за по-високи скорости на данни или потребители на IоT машини.

Огромното количество честотна лента в милиметровия честотен обхват, което е 25 пъти повече от това, използвано понастоящем за 3G/4G комуникации е илюстрирано на фиг. $1[2]$. 


\section{Годишник Телекомуникации 2019, том 6, с. 161-170}

\section{Yearbook Telecommunications 2019, vol. 6, p. 161-170}

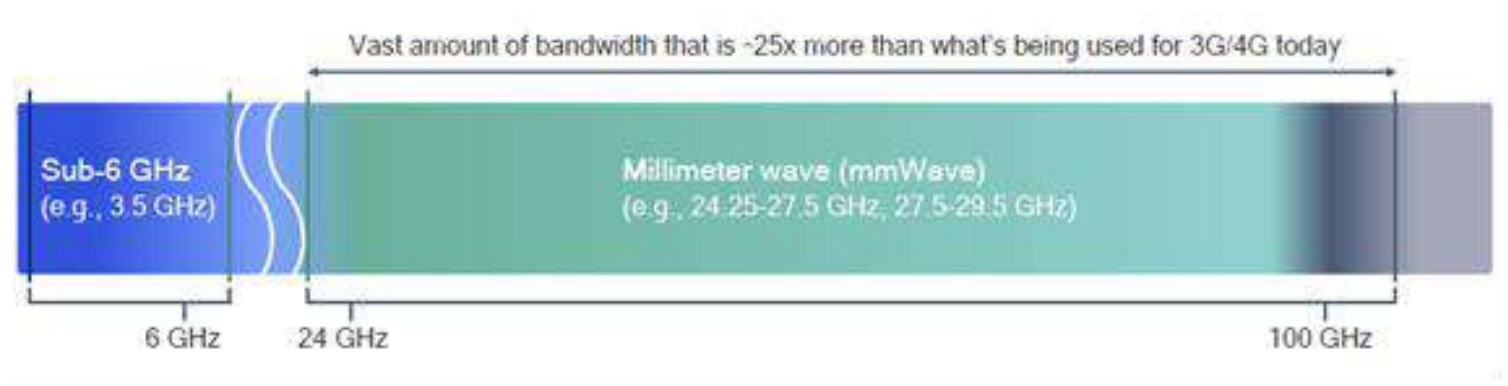

Фиг.1 Честотен спектьр за 5G в mmWave честотен обхват

Един от проблемите с използването на mmWave e, че много високочестотните 5G сигнали не могат да се разпространяват на големи разстояния и не преминават много добре от закрито към открито и обратно, т.е има голямо затихване при преминаване през стени. Въпреки това, използването на масивни МIMO антени и формирането на остронасочени лъчи гарантира, че строгото изискване за пряка видимост не е задължително при използване на милиметрови вълни. Сигнал в mmWave обхват може да не проникне в сградите, но ще се отрази от тях и пак ще осигури сигнал с приемливо качество. При осигуряване на покритие в закрити пространства ще трябва да се разчита повече на сигнали в обхвата под $6 \mathrm{GHz}$ и на LTE сигнали.

Използвайки милиметровият честотен обхват за 5G мрежи ще се удовлетвори непрекъснато нарастващото търсене на мобилни широколентови услуги. Предвижда се в периода от 2013г. до 2024г. мобилният трафик на данни да се повиши около 60 пъти. Очаква се в глобален мащаб мобилният трафик на данни да достигне 136B GBits, като $25 \%$ от него ще се генерира от $5 \mathrm{G}$ мрежите - $1 / 3$ повече от днешния трафик на 4G/3G/2G мрежите [7].

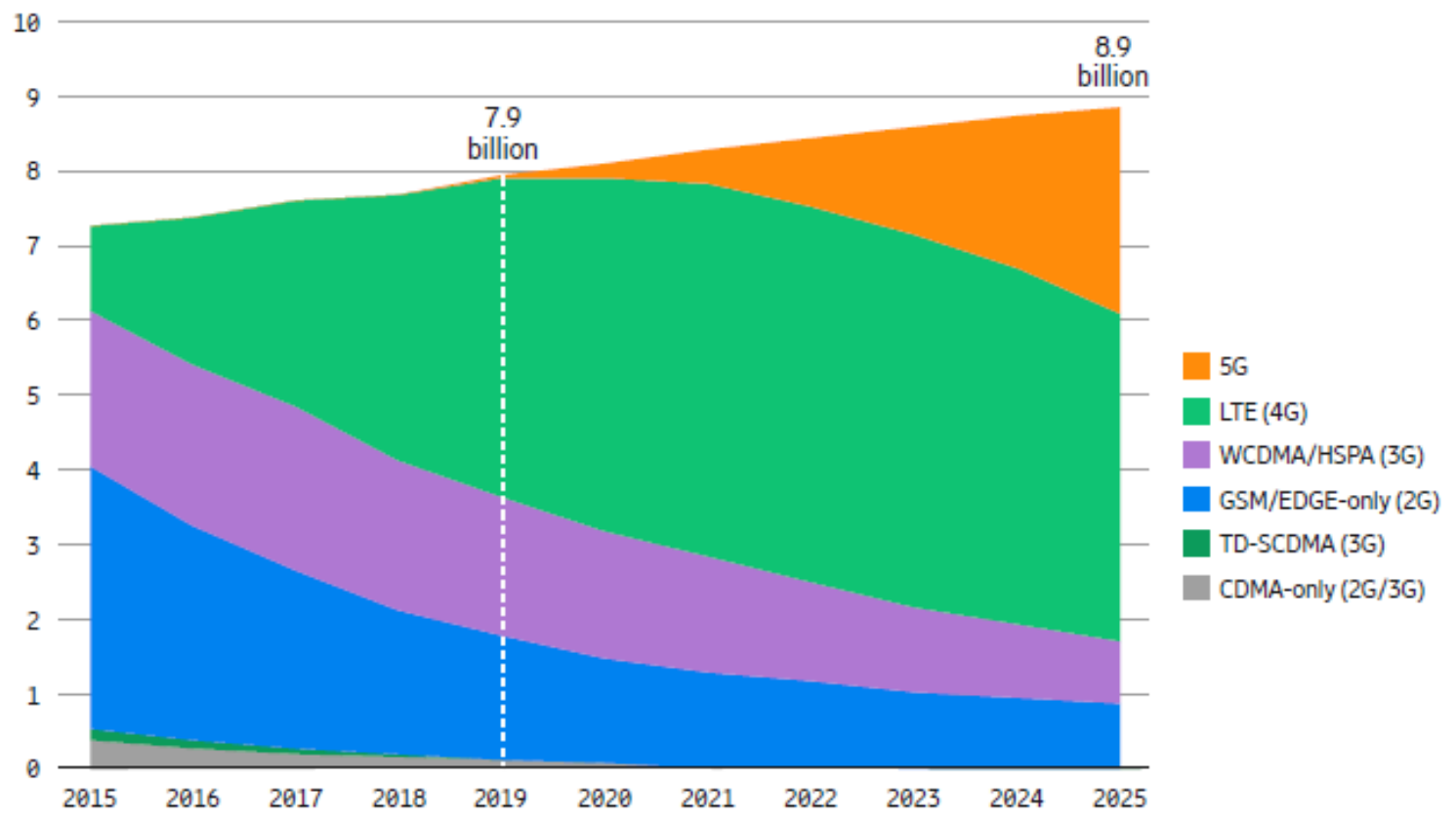

Фиг. 2 Брой мобилни потребители според използваната технология (в билиони) [7] 
Необходимостта от допълнителен радиочестотен спектьр за 5G се базира не само на повишеното търсене, но и на техническите изисквания към този тип мрежи, например:

- Много ниската латентност и много високата скорост за пренос на данни изискват по-големи съседни ленти от честотния спектър.

- Осигуряване на възможност за развитие на Интернет на нещата (IоT), изкуствен интелект, облачни технологии, големи масиви от данни, геопространствени анализи и други нови технологии.

- Хармонизираните честотни ленти за IMT в глобален мащаб ще улеснят международния роуминг и ще са от полза за развитие на световната икономика

\section{3. РЕШЕНИЯ НА СВЕТОВНАТА КОНФЕРЕНЦИЯ ПО РАДИОСЬОБЩЕНИЯ WRC-2019}

Резултатите от наскоро завършилата WRC-19 поставиха началото на вълнуващи нови възможности за 5G. В същото време подготовката за WRC-23 вече дава възможност де се приоритизира разгръщането и покритието с $5 \mathrm{G}$ мрежи.

„WRC-19 проправи пътя към нови, по-иновативни начини за свързване на света, използвайки както наземни, така и спътникови комуникационни технологии“, заяви генералният секретар на ITU Хулин Джао. 5G е водеща технология за широколентов достъп, която се появява в новите индустриални разработки и чрез нея и хората в найотдалечените райони също ще получат по-добър достъп на приемливи цени“ [3].

WRC-19 идентифицира допълнителни глобално хармонизирани честотни ленти в милиметровия обхват за Международни мобилни телекомуникации (IMT), включително IMT-2020 (известни като 5G мобилни комуникации), давайки възможност за разработване на различни сценарии за използването им за усъвършенствани широколентови комуникации, комуникации между машини и високонадеждни комуникации с много ниска латентност.

Ha WRC-19 делегатите направиха голяма стьпка в предоставянето на разположение на високочестотен mmWave спектьр в честотни обхвати $26 \mathrm{GHz}$ и $40 \mathrm{GHz}$. Постигнат беше баланс между предоставянето на нови възможности за mmWave 5G за комуникации с висок капацитет и защитата на съществуващите радиоуслуги. Разрастващата се глобална екосистема около mmWave спектьр получи голям тласьк в подкрепа на развитието на достьпни услуги и устройства.

Допълнително идентифицираните ленти осигуряват възможност за стандартизиране на разгръщането на 5G (IMT 2020). Прогнозите сочат, че решенията на WRC-2019 ще стимулират множество приложения, улесняващи интелигентните транспортни системи, създаването на интелигентни градове като същевременно ще позволяват ефективни действия в областта на климата, подобрени здравни грижи, устойчиви селскостопански практики и по-голяма енергийна ефективност.

Очаква се IMT-2020 да продължи да се развива и след 2020 г., като изпитванията на $5 \mathrm{G}$ мрежи за търговски дейности вече са в ход, за да подпомогнат оценяването на разработените до момента технологии и честотни ленти, които могат да бъдат използвани за този тип комуникации [12].

При идентифицирането на честотните ленти 24,25-27,5 GHz, 37-43,5 GHz, 45,5-47 $\mathrm{GHz}, 47,2-48,2$ и 66-71 GHz за разгръщане на 5G мрежи, WRC-19 също предприе мерки за осигуряване на подходяща защита на службите за проучване на Земята, Спътниковите служби, включително метеорологични и други пасивни служби в съседни честотни ленти. Бяха представени резултати от проучвания за защита на спътниковата служба за изследване на Земята (EESS), както и на метеорологичните и други пасивни служби в съседни ленти, като например, службата за космически изследвания (SRS), за да се гарантира, че космическият мониторинг на земята и атмосферата ще се извършва без 
Годишник Телекомуникации 2019, том 6, с. 161-170

Yearbook Telecommunications 2019, vol. 6, p. 161-170

eISSN 2534-854X

https://telecommunications.nbu.bg/bg/godishnik-telekomunikacii

DOI: https://doi.org/10.33919/YTelecomm.19.6.16

причиняване на вредни смущения. Спътниковите служби, подпомагащи метеорологията и климатологията, които имат за цел да защитят човешкия живот и природните ресурси, ще бъдат защитени от вредни радиочестотни смущения, както и системите, използвани от радиоастрономите за изследване на дълбокия космос. Бяха предприети стьпки, за да се гарантира, че радиоастрономическите станции ще бъдат защитени от всякакви вредни радиосмущения от други космически станции или спътникови системи в орбита.

На Конференцията е идентифициран общо 17,25 GHz спектьр за IMT в сравнение с $1,9 \mathrm{GHz}$ честотна лента, налична преди WRC-19. От този спектьр $14,75 \mathrm{GHz}$ са хармонизирани в световен мащаб, достигайки 85\% глобална хармонизация.

Държавите-членки на Европейския съюз посочиха, че ще осигурят възможност за използване на честотни ленти с обща широчина най-малко $1 \mathrm{GHz}$ от $26 \mathrm{GHz}$ обхват преди края на 2020 г., в съответствие с Кодекса на ITU и това вероятно ще бъде в честотната лента от 26,5-27,5 GHz, както препоръчва Групата по политика в областта на радиоспектъра (Radio Spectrum Policy Group - RSPG) към CEPT [9].

В допълнение, WRC-19 също определи план за проучвания за идентифициране на честоти за нови компоненти на 5G. Например, предвижда се да се улесни мобилната свързаност чрез атмосферни IMT базови станции на голяма надморска височина (High Altitude IMT Base Stations -HIBS). HIBS може да се използват като част от наземните IMT мрежи за осигуряване на мобилна свързаност в необсужени райони, които е трудно да бъдат обхванати от наземните IMT базови станции на разумна цена.

Пьрвите пълномащабни тьрговски внедрения за 5G се очакват към края на 2020 г.

ITU-R ще продължи да работи за осигуряване на стабилни международни регулации, достатъчен спектьр и подходящи стандарти за IMT-2020 - мрежа за достьп и основната мрежа, за да позволи успешното внедряване на $5 \mathrm{G}$ на регионално и международно ниво.

\section{4. ПО-МАЛЬК ОБХВАТ, ПОВЕЧЕ СМУЩЕНИЯ И ПРОБЛЕМИ С РАЗПРОСТРАНЕНИЕТО В ЗАКРИТИ ПРОСТРАНСТВА}

Ефективният обхват на радиосигнала намалява пропорционално на квадрата на честотата. Това има голямо влияние върху капиталовите разходи на клетъчната радио мрежа. Въпреки че много 5G мрежи, които в момента са в процес на тестване, ще използват много по-ниските честотни ленти, тези в милиметровия честотен обхват, които се предлагат за в бъдеще, могат да имат обхват на разпространение на сигнала само от порядъка на стотици или дори десетки метра. Сигналите с по-висока честота също са обект на повече смущения от атмосферните условия - дъжд, сняг, мъгла и препятствия мокра зеленина или сгради и техните стени. Това означава, че при по-високи честоти използването в закрити пространства може да бъде проблемно, ако се базира на проникване през стена или прозорец. Следователно, в близко бъдеще ще се разчита повече на повторното използване на съществуващите UHF диапазони, както и на тези, които са малко по-горе в диапазона от 3 до $10 \mathrm{GHz}$ („среден диапазон“), за да се осигурят 5G сигнали с по-голям физически обхват и по-малко технически предизвикателства [6,7].

При по-високи честоти и по-малки зони на покритие, базовите станции ще бъдат по-пльтно разположени в дадена зона, за да осигурят качествено покритие, без места с липса на обхват („бели петна“). Като реален се прогнозира обхват от 20 до 150 метра с използване на „малки клетки“. Радиус на клетката от 20 метра би означавал около 800 базови станции на квадратен километьр (или точки за безжичен достьп с малка зона на покритие (small area wireless access points - SAWAPs). Този термин е използван в 
Европейския кодекс за електронни съобщения (ЕЕСС) [13]. Това контрастира с 3G и 4G, мрежите, които използват големи или „макро“ клетки. Традиционно те предлагат обхвати от 2-15 km или повече и така могат да покрият по-голяма площ, но с по-малко едновременни потребители, тъй като имат по-малко индивидуални канали [7].

Анализът на потенциалните сценарии за съвместна работа (в един и същ географски район и в съседни честотни ленти) и оценка на перспективите за развитие на бизнес средата показва, че:

- От потенциалните проблеми, свързани със съвместното функциониране на различните служби, проучванията за съвместното използване на спектьра с фиксираните линии в обхват $26 \mathrm{GHz}$ трябва да продължат.

- Решението да се защити спътниковата служба за изследване на Земята (EESS) (пасивна), функционираща в честотния обхват под $24 \mathrm{GHz}$ със строги гранични стойности за извънлентовите излъчвания в $26 \mathrm{GHz}$ обхват, налага подход на „максимално съответствие“, с последици за практическата наличност на долната част на $26 \mathrm{GHz}$ обхват. Това може да има по-голямо влияние по отношение на административния процес за присвояване на спектьра (т.е. широчините на честотните блоковете, достьпни за операторите), отколкото върху ограничаване на капацитета, предвид относително дългия период, предвиден за търсене и усвояване на милиметровите вълни за 5G.

- При изграждането на 5G в милиметровия обхват не се очакват значителни ограничения при честотната координацията със земни станции (EESS и SRS приемане и FSS - излъчване), поради малкия брой на участващите обекти и тяхното местоположение в селски региони. Доклад СЕРТ 68 [22] също така отбелязва „необходимостта да се запази възможността за разполагане на допълнителни земни станции в държавите-членки на ЕС...“. Необходимите технически инструменти за координация с тези служби вече съществуват.

- Проучвания в СЕРТ РТ1 показват, че не се предвиждат значителни проблеми със съвместното функциониране в честотната лента 40,5-43,5 $\mathrm{GHz}$, идентифицирана като „второто мнение“ на RSPG, като приоритетна лента за втория етап на разгръщане на $5 \mathrm{G}$.

- Честотната лента 66-71 GHz, идентифицирана като другата 5G честотна лента на втория етап, е отчасти привлекателна благодарение на това, че е съседна на съществуващата нелицензирана радиочестотна лента 57-66 GHz. Потенциальт за смущения в съседна честотна лента между двете разпределения е проучен, но е малко вероятно да бъде по-проблематичен от този между различни потребители в една и съща лента.

\section{28 GНZ БЕКХОЛ НА ОТКРИТО ЗА ФИКСИРАН БЕЗЖИЧЕН ДОСТЬП И ДВИЖЕЩИ СЕ ТОЧКИ ЗА ДОСТЫП}

Много е вероятно $28 \mathrm{GHz}$ да се използва за първо внедряване на 5G в Южна Корея, САЩ и Япония, въпреки че тази честотна лента беше изключена от кандидатите за IMT на WRC-15.

Въпреки че честотните ленти около $28 \mathrm{GHz}$ с приоритет за $5 \mathrm{G}$ в тези страни, очевидно има честотни предпочитания в различните държави. За да се реши този проблем, $3 \mathrm{GPP}$ предлага спектьрът от $24,25-29,5 \mathrm{GHz}$ да се разглежда като една единствена лента и използването на конкретни канали да се базира на националните планове за разпределение на честотите.

След WRC-15, много доставчици започнаха да разработват сравнително евтини 28 $\mathrm{GHz}$ технологии, което доведе и до решението на Intel да поддържа елементна база за този честотен обхват [24]. 
Годишник Телекомуникации 2019, том 6, с. 161-170

Yearbook Telecommunications 2019, vol. 6, p. 161-170

eISSN 2534-854X

https://telecommunications.nbu.bg/bg/godishnik-telekomunikacii

DOI: https://doi.org/10.33919/YTelecomm.19.6.16

Изборьт на $28 \mathrm{GHz}$ обхват е мотивиран от няколко причини:

- Първо, около $28 \mathrm{GHz}$ има достатъчно свободен лицензиран mmWave спектьр, който не се използва достатьчно. За този спектьр е доказано, че поддържа клетъчни комуникации с обхват от 500 метра $[1,23]$.

- На второ място, $28 \mathrm{GHz}$ обхват е переспективен, тъй като дава възможност за многолъчево разпространение на радиовълните за разлика от повисокочестотните обхвати, т.е. може да се използва за комуникации без пряка видимост. Освен това, допълнително важно предимство при експлоатацията на $28 \mathrm{GHz}$ обхват за безжичен бекхол е възможността за повторна употреба на 3GPP LTE функционалностите. Например, 3GPP LTE позволява да се използва повторно физическият слой, който първоначално е проектиран да работи при носещи честоти около $2 \mathrm{GHz}$ и да се прилага на по-високи честоти до $40 \mathrm{GHz}$ за бекхол на малки клетки $[7,12]$. Това изисква малки модификации с цел увеличаване на честотното отстояние между потребителите. По този начин ще се постигне икономически ефективно адаптиране на съществуващата технология за приспособяване към новите изисквания за 5G.

\section{5G ЕЛЕКТРОМАГНИТНИ ИЗЛЬЧВАНИЯ И БЕЗОПАСНОСТ}

Съществува значително безпокойство относно възможното въздействие върху здравето и безопасността на хората, произтичащо от потенциално много по-голямо излагане на радиочестотни електромагнитни излъчвания от 5G мрежи [20]. Повишената експозиция може да се дължи не само на използването на много по-високи честоти в 5G, но и на потенциала за агрегиране на различни сигнали, тяхната динамична сьщност и комплексните ефекти на смущенията, особено в гъсти градски райони [9].

Изльчваните радиочестотни полета от $5 \mathrm{G}$ мрежи са доста различни от тези от предишните поколения, поради начина на формиране на лъчите в двете посоки - от базова станция до потребителско устройство и обратно. Въпреки че полетата са силно фокусирани чрез лъчите, те варират бързо с времето и придвижването на потребителя, което затруднява прогнозите, тъй като нивата на сигнала и диаграмата на излъчване на антената си взаимодействат като затворена система. Действителните нива все още не са проучени в реални ситуации, различни от тестовите измервания [21].

Преминаването към 5G ще бъде свързано с изграждане на голям брой малки клетки, някои от които ще работят в ленти от mmWave обхват. Излагането на населението на електромагнитни полета не е право пропорционално на броя на базовите станции; въпреки това, промяната със сигурност ще окаже влияние на нивата на експозицията. Излъчената мощност в милиметровите обхвати ще бъде много по-ниска от тази на използваните в момента макро клетъчни мрежи, но наличието на голям брой базови станции, заедно с използването на масивни МIMO антени за формиране на остро насочени лъчи означава, че експозицията във всеки даден момент може да варира значително в зависимост от за това на какво разстояние се намира даден потребител спрямо обслужващата го базова станция и към кои местоположения изпраща сигнал.

Въз основа на проучвания и моделиране на използването на mmWave за 5G, проведени в рамките на Европейския съюз се прогнозира, че всяко увеличаване на експозицията на населението с електромагнитни полета, причинено от преминаването към 5G и малки клетки, може да причини само много малко увеличение на нивата на облъчване [10]. Това до голяма степен съответства на резултатите от проведени проучвателни измервания от френската агенция по честотите (ANFR), свързани с 
разполагането на малки клетки в град Annecy [25], при което е установено увеличение на електромагнитното поле само $0,1 \mathrm{~V} / \mathrm{m}$ (до максимум $0,5 \%$ от нормите на ICNIRP). Проучването на ANFR е проведено в мальк град при сценарий на използване на 4G малки клетки, което не симулира напълно внедряване на 5G, но въпреки това представлява важна стъпка към прогнозиране на нивата на облъчване от такъв тип мрежи в реални условия.

Основният проблем е, че към днешна дата не е възможно точно да се симулират или да се измерят в реални условия нивата на електромагнитните полета, създавани от 5G мрежи.

\section{6. ЗАКЛЮЧЕНИЕ}

Групата на ITU, отговаряща за IMT-2020 или 5G, продължава оценяването на предложените технологии, които ще позволят на мрежовите оператори да предлагат $5 \mathrm{G}$ услуги с усъвършенствани характеристики на своите потребители през следващото десетилетие. ITU планира стандартите, регламентиращи всички 5G приложения, включително използването на милиметровия честотен обхват, да бъдат въведени през 2020 г., което е в интерес на цялата телекомуникационна общност.

В милиметровия честотен обхват има достатъчно неразпределен честотен спектьр, така че тези обхвати предоставят възможност за осигуряване на по-широка честотна лента, респективно повече канали и по-високи скорости за пренос на данни.

Очаква се на операторите да се предоставя честотната лента с широчина от порядъка на $100 \mathrm{MHz}$ до $400 \mathrm{MHz}$, в сравнение с 10 до $20 \mathrm{MHz}$ за UHF каналите.

Предвид ниския риск от вредни смущения, основната цел на Европейската комисия е наблюдение на разпределението и предоставянето на честотен спектьр в милиметровия обхват за внедряване на новите $5 \mathrm{G}$ технологии в държавите-членки. То трябва да бъде съобразено с целите, определени в Европейския кодекс за електронни съобщения, така че да се осигури наличност на честотен спектьр в одобрените за целта хармонизирани честотни ленти за Европейската общност.

След като бъдат приети хармонизирани стандарти за измерване на електромагнитните полета, отговорните органи на държавите-членки трябва да разработят процедури за измерване на нивата на облъчване с електромагнитни полета от 5G (включително 5G в милиметровия обхват), които трябва да отговарят на европейските изисквания, както е посочено в Препоръка на Съвета от 1999 г..

В бъдеще може би ще е необходимо да се извършват и регулярни полеви тестове (драйв тестове).

\section{ЛИТЕРАТУРНИ ИЗТОЧНИЦИ (REFERENCES):}

[1] Sakaguchi K., and all, Where, When, and How mmWave is Used in 5G and Beyond, [viewed 18.06.2020]. Available from: https://arxiv.org/ftp/arxiv/papers/1704/1704.08131.pdf

[2] Qualcomm, Breaking the wireless barriers to mobile 5G NR mmWave, May 2019, [viewed 17.06.2020]. Available from: $\quad$ https://www.qualcomm.com/media/documents/files/5g-nr-mmwave-deployment-strategypresentation.pdf

[3] Mazar H., ITU WRC-19, additional spectrum allocations for IMT-2020 (5G mobile). International conference: EMF and the future of telecommunications, December 2019. [viewed 18.06.2020]. Available from: https://www.researchgate.net/publication/337812602_ITU_WRC-19_additional_spectrum_allocations_for_IMT2020_5G_mobile/references

[4] Stancheva A., P.Tsvetkov, V. Kadrev G. Petrov. New approach regulation for radio equipment, In Proceedings of the XIV International Conference "'Challenges in Higher Education and Re-search in XXI Century, TU - Sofia, English Language Faculty of Engineering, 31 May-3 June 2016, pp,70-73, Sozopol, Bulgaria, ISBN:978-954-580$365-9$.

[5] Petrov G., A.Stancheva, V.Kadrev Specialized databases for spectrum management research, analysis and forecasting of the effects of working electromagnetic fields, НБУ, Годишник Телекомуникации, стр. 118-126, ISSN 2534-854X (online), 2014, https://www.ceeol.com/search/journal-detail?id=1546 
Годишник Телекомуникации 2019, том 6, с. 161-170

Yearbook Telecommunications 2019, vol. 6, p. 161-170

eISSN 2534-854X

https://telecommunications.nbu.bg/bg/godishnik-telekomunikacii

DOI: https://doi.org/10.33919/YTelecomm.19.6.16

[6] Weissberger A. WRC 19 Wrap-up: Additional spectrum allocations agreed for IMT-2020 (5G mobile), November 2010. [viewed 18.06.2020]. Available from: https://techblog.comsoc.org/2019/11/22/wrc-19-wrap-upadditional-spectrum-allocations-agreed-for-imt-2020-5g-mobile/

[7] Станчева А., В. Къдрев. Смущения между LTE мобилни потребителски устройства, Годишник "Телекомуникации" 2017, ISSN 2534-854X (online), Нов български университет, София, том 4, 2017, стр. 23-34, https://www.ceeol.com/search/journal-detail?id=1546. Stancheva A., V. Kadrev. Smushteniya mezhdu LTE mobilni potrebitelski ustroystva, Godishnik "Telekomunikatsii" 2017, ISSN 2534-854X (online), Nov balgarski universitet, Sofiya, tom 4, 2017, str. 23-34, https://www.ceeol.com/search/journal-detail?id=1546.

[8] BLACKMAN, C., FORGE, S., 5G Deployment: State of Play in Europe, USA and Asia, Study for the Committee on Industry, Research and Energy, Policy Department for Economic, Scientific and Quality of Life Policies, European Parliament, Luxembourg, 2019.

[9] Ericsson Mobility Report, June, 2020. [viewed 19.06.2020]. Available from: https://www.ericsson.com/49da93/assets/local/mobility-report/documents/2020/june2020-ericsson-mobility-

report.pdf

[10] Frédéric P, MANERO C., ROPERT S., ENJALBAL A., LAVENDER T., JERVIS V., RUDD R. MARCUS J., Study on using millimetre waves bands for the deployment of the $5 \mathrm{G}$ ecosystem in the Union, European Union, 2019, ISBN 978-92-76-04282-2

[11] Paolini M., 5G in Europe: More than a wireless upgrade. The wireline network evolution in preparation for 5G, Senza Fili, 2018. [viewed 20.06.2020]. Available from: https://media.ciena.com/documents/SenzaFili-CienaTransport.pdf

[12] Къдрев В., А. Станчева, Г. Петров. Анализ на производителността на каналите за сигнализация в клетъчни мрежи. Научна конференция с международно участие на НВУ „В. Левски”, В. Търново, 2021.10.2016. В: Сб-к доклади на конференцията, стр. 771-782, ISSN 2367-7481. Kadrev V., A. Stancheva, G. Petrov. Analiz na proizvoditelnostta na kanalite za signalizatsiya v kletachni mrezhi. Nauchna konferentsiya $s$ mezhdunarodno uchastie na NVU „V. Levski”, V. Tarnovo, 20-21.10.2016. V: Sb-k dokladi na konferentsiyata, str. 771-782, ISSN 2367-7481.

[13] ITU-R, "IMT Vision - Framework and overall objectives of the future development of IMT for 2020 and beyond," Recommendation M. 2083-0, Sep. 2015.

[14] Александрова Е., А. Станчева, А. Латев, М. Заяков, Българското участие и резултати от Радиоасамблеята (RA-15) и Световната радиоконференция (WRC-15), Сборник доклади на Дванайсета Научна конференция с международно участие „Космос, екология, сигурност, ISSN 1313-3888, 2-4 11. 2016 , София, България, с. 94-99. Aleksandrova E., A. Stancheva, A. Latev, M. Zayakov, Balgarskoto uchastie i rezultati ot Radioasambleyata (RA-15) i Svetovnata radiokonferentsiya (WRC-15), Sbornik dokladi na Dvanayseta Nauchna konferentsiya s mezhdunarodno uchastie „Kosmos, ekologiya, sigurnost, ISSN 1313-3888, 2-4 11. 2016, Sofiya, Balgariya, s. 94-99

[15] DIRECTIVE (EU) 2018/1972 OF THE EUROPEAN PARLIAMENT AND OF THE COUNCIL of 11 December 2018 establishing the European Electronic Communications Code. [viewed 21.06.2020]. Available from: https://eur-lex.europa.eu/legal-content/EN/TXT/PDF/?uri=CELEX:32018L1972\&from=EN

[16] 3GPP TR22.891, "Study on New Services and Markets Technology Enablesr," V14.2.0, Sep. 2016.

[17] Симеонова Цв. Методи за анализ на риска и възможности за приложение в оценката на безопасността на осигурителните системи. В сб. на международна научна конференция на БСУ, том 3, стр. 163-172, ISBN 978-954-9370-80-5, Бургас, 2011. Simeonova TSv. Metodi za analiz na riska i vazmozhnosti za prilozhenie v otsenkata na bezopasnostta na osiguritelnite sistemi. $V$ sb. na mezhdunarodna nauchna konferentsiya na BSU, tom 3, str. 163-172, ISBN 978-954-9370-80-5, Burgas, 2011.

[18] Симеонова Цв. Изследване влиянието на средствата за сигнализация и комуникации върху индивидуалния риск за участниците в транспортния процес. Автореферат на дисертация за придобиване на ОНС „доктор”, ВТУ „Тодор Каблешков”, 2013 г. Simeonova TSv. Izsledvane vliyanieto na sredstvata za signalizatsiya i komunikatsii varhu individualniya risk za uchastnitsite $\mathrm{v}$ transportniya protses. Avtoreferat na disertatsiya za pridobivane na ONS ,, doktor”, VTU „Todor Kableshkov”, $2013 \mathrm{~g}$.

[19] Bertenyi, Balazs (2017), 5G NR Standards in 3GPP, [viewed 21.06.2020]. Available from: https://images.samsung.com/is/content/samsung/p5/global/business/networks/insights/event/the-silicon-valley-5gsummit-2017/Session-1_3GPP Balazs-Bertenyi.pdf.

[20] Blackman, Colin and Simon Forge (2016), European Leadership in 5G, In-Depth Analysis, European Parliament, IP/A/ITRE/ 2016-05. [viewed 21.06.2020]. Available from:

http://www.europarl.europa.eu/RegData/etudes/IDAN/2016/595337/IPOL_IDA(2016)595337_EN.pdf.

[21] Къдрев В., П. Цветков, А. Станчева, Г. Илиев. Анализ на параметрите на излъчваните електромагнитни полета от мобилни устройства и системи, Сборник доклади от Научна конференция "Актуални проблеми на 
сигурността”, Наџионален военен университет „Васил Левски”, ISBN:978-954-753-200-7, 16-18.10.2013, B. Търново, том 7, pp. 53-63. Kadrev V., P. TSvetkov, A. Stancheva, G. Iliev. Analiz na parametrite na izlachvanite elektromagnitni poleta ot mobilni ustroystva i sistemi, Sbornik dokladi ot Nauchna konferentsiya "Aktualni problemi na sigurnostta”, Natsionalen voenen universitet ,, Vasil Levski”, ISBN:978-954-753-200-7, 16-18.10.2013, V. Tarnovo, tom 7, pp. 53-63.

[22] Станчева А. В. Къдрев, Г. Петров. Оценка на риска при използване на мобилни устройства и защита на човека от електромагнитни полета, Сборник доклади от Годишна университетска научна конференция Национален военен университет „Васил Левски”, ISNN 1314-1937, 3-4.07.2014, В. Търново, Том 11, с.169178. Stancheva A. V. Kadrev, G. Petrov. Otsenka na riska pri izpolzvane na mobilni ustroystva i zashtita na choveka ot elektromagnitni poleta, Sbornik dokladi ot Godishna universitetska nauchna konferentsiya Natsionalen voenen universitet ,, Vasil Levski”, ISNN 1314-1937, 3-4.07.2014, V. Tarnovo, Tom 11, s.169-178.

[23] CEPT Report 68, Report B from CEPT to the European Commission in response to the Mandate "to develop harmonised technical conditions for spectrum use in support of the introduction of next-generation (5G) terrestrial wireless systems in the Union", Harmonised technical conditions for the 24.25-27.5 GHz ('26 GHz') frequency band 6 July 2018.

[24] Александрова Е., А. Станчева, М. Заяков. Ефективно използване на спектрално-орбиталните ресурси, Сборник доклади на осма научна конференция с международно участие „Космос, екология, сигурност, 4-6. 12.2012, София. Aleksandrova E., A. Stancheva, M. Zayakov. Efektivno izpolzvane na spektralno-orbitalnite resursi, Sbornik dokladi na osma nauchna konferentsiya s mezhdunarodno uchastie „Kosmos, ekologiya, sigurnost, 4-6. 12.2012, Sofiya

[25] Балабанов Б., Г. Петров, А. Станчева. Оразмеряване и оценка на радиочестотния орбитален ресурс, Годишник "Телекомуникации” 2016, ISSN 2534-854X (online), Нов български университет, София, том 3, 2016, c. 37-45, https://www.ceeol.com/search/journal-detail?id=1546. Balabanov B., G. Petrov, A. Stancheva. Orazmeryavane i otsenka na radiochestotniya orbitalen resurs, Godishnik "Telekomunikatsii" 2016, ISSN 2534854X (online), Nov balgarski universitet, Sofiya, tom 3, 2016, s. 37-45, https://www.ceeol.com/search/journaldetail?id=1546

[26] Samsung Electronics Co., Ltd. “5G Vision White Paper”, February 2015. [viewed 22.06.2020]. Available from: https://images.samsung.com/is/content/samsung/p5/global/business/networks/insights/white-paper/5g-vision/globalnetworks-insight-samsung-5g-vision-2.pdf

[27] Intel Inc., "Intel Announces World's First Global 5G Modem,”Jan. 2017. [viewed 22.06.2020]. Available from: https://newsroom.intel.com/newsroom/wpcontent/uploads/sites/11/2017/01/5G-modem-fact-sheet.pdf

[28] ANFR, CONNECTIVITE URBAINE Rapport technique sur l'expérimentation de petites antennes à Annecy pour favoriser l'accès au très haut débit mobile, Avril 2017, [viewed 22.06.2020]. Available from: https://www.anfr.fr/fileadmin/mediatheque/documents/Actualites/2017-04-26__Rapport résultats_Annecy.pdf.

\section{Информация за автора:}

доц. д-р инж. Росен Пасарелски, Департамент "Телекомуникации” НБУ, София, ул. Монтевидео № 21, 2609, Тел.: 02 8110616, e-mail: rpasarelski@ nbu.bg

\section{Contacts:}

Assoc. Prof. Rosen Pasarelski, PhD, New Bulgarian university, Department Telecommunication, Sofia, 21 Montevideo St., tel.: 35928110616 ; e-mail: rpasarelski@ nbu.bg

Дата на постъпване на ръкописа (Date of receipt of the manuscript): 01.09.2019 Дата на приемане за публикуване (Date of adoption for publication): 27.09.2019 